terpretamos como correspondiente a las operaciones técnicas de delimitación del ager per extremitatem mensura comprehensus, lo que nos parece lo más probable, seria posible fecharlo incluso en época augustea ${ }^{20}$, fecha que parece excesivamente temprana para la zona. No nos parece descartable una datación en épo-

20 Focke Tannen Hinrichs: Die Geschichte der gromatischen..., 115, cit. (n. ${ }^{\circ 10)}$ : Histoire des institutions..., 121. cit. (n."10), piensa que la medición del ager per extremitatem mensura comprehensus en Lusitania fue iniciativa de Augusto y simultánea de las operaciones de asignación de tierras en Augusta Emerita, en conexión con la reestructuración de la nueva provincia. Es de destacar que los ca flavia en relación con la politica de revisión del catastro llevada a cabo por Vespasiano ${ }^{21}$. Al respecto queremos destacar que la pobreza y mala factura del monumento epigráfico no debe llevarnos a presuponer necesariamente una datación tardia, por otra parte no descartable.

termini CIL, II, 857,858 y 859 que se refieren a los territorios de Bletissa. Mirohriga y Salmantica llevan datación del año $6 \mathrm{~d}$. C

2 Sobre la politica de revisión del catastro llevada a cabo por Vespasiano vid. Hinrichs, Focke Tannen: Die Ges chichte der gromatischen..., 128-146, cit. (n. $\left.{ }^{\circ} 10\right)$ : Histoire des institutions.., 135-154, cit. (n. $\left.{ }^{\circ} 10\right)$.

\title{
LOS MOSAICOS COMO DOCUMENTOS PARA LA HISTORIA DE LA HISPANIA TARDÍA (SIGLOS IV-V)
}

\author{
POR \\ JAVIER ARCE \\ Escuela Española de Historia y Arqueología del C.S.1.C. - Roma
}

RESUMEN

El presente artículo examina algunos ejemplos de mosaicos relevantes hallados en contextos arqueológicos de la Hispania tardorromana (Iv-v d. C.) e investiga su validez como "fuente para la Historia tardorromana". Recientes investigaciones $\mathrm{e}$ interpretaciones han pretendido verlos como una prueba de religiosidad de los propietarios de las villae en las que fueron encontrados.

Mi propuesta es que han sido "superinterpretados" y que es necesario ser muy cautos cuando se realizan dichos estudios, teniendo en cuenta el contexto histórico de la producción musiva del período tardorromano.

\section{SUMMARY}

The present article examines some examples of relevant mosaics founded in archaeological context of Late Roman Spain (IV-v A. D.) and investigates their validity as "source for the Late Roman History». Recent research and interpretations of them claim their meaning as a proof of religious commitments for their owners or even ownership of the villae in which were found.

The proposal is that they have been overinterpreted and that it is necessary to be very cautious in its study taking into account the historical background of mosaic production of the Late Roman period. 
El historiador Amiano Marcelino, gran testigo de los hechos y de la sociedad tardoantigua, lo dejó claramente escrito: la aristocracia tardorromana de su tiempo era, en general, inculta e ignorante. En un pasaje en el que critica la sociedad tardorromana que lo circunda, el historiador antioqueno señala que en estos circulos de senadores y ricos propietarios «en vez de al filósofo se prefiere al cantanten (pro philosopho, cantor); $\mathrm{y}$ frente al orador se tiene más consideración con el director de escena (in locum oratoris doctor artium ludicrarum accitur). Consecuentemente - sigue Amiano-- las bibliotecas (de Roma) estaban cerradas para siempre como si fueran tumbas (et bibliothecis sepulchrorum ritu in perpetuum clausis)' '. Este es un texto, ciertamente, que debe ser matizado y contextualizado en la propia dinámica de la obra amianea, pero aún así, es un testimonio que se debe contrastar con la visión, generalizada en exceso, que hemos asignado a la sociedad tardorromana identificándola, unilateralmente, con los Nicómacos, Símacos, Libanios o Synesios. Hemos recreado uniformemente y sin distinciones, un modelo de gobernadores, perfectissimi, ilustrissimi o eminentissimi que, probablemente, no responden, en la mayoria de los casos, a la realidad - de la que por otro lado desconocemos casi todo-. Se ha hecho de estos personajes latifundistas todos iguales, sabios, conocedores del pasado y de la más intrincada filosofía, sabedores de los más complicados simbolismos cripticos y elitistas. $Y$ esto ha sucedido, a veces, en las interpretaciones de los mosaicos pavimentales de las villae romanas de época tardía.

\section{EL MOSAICO DE LA VILLA DE «LA MALENA»}

Un reciente articulo sobre los mosaicos de la villa romana de La Malena, cercana a Zaragoza (Caesaraugusta), ha visto en la escena central la representación de las bodas de Cad-

1 Am. Marc. 28.4.14 con Alan Cameron: Observations on the distribution and ownership of Late Roman, Silver Plate, JRA, 5, 1992, págs. 178-185. mo y Armonia ${ }^{2}$. Esta identificación puede ser correcta o no serlo. En este caso particular yo creo que no lo es, debido a dos hechos fundamentales: 1) a que no existe ninguna propuesta de paralelo en toda la iconografia antigua que permita inferir con certeza tal identificación y 2) a que disponemos de una solución mucho más sencilla, bien atestiguada en la documentación antigua - literaria e iconográfica-que permite proponer que se trata de una escena común de matrimonio a la que asisten los dioses protectores y garantes del acto, como testimonian, por ejemplo, Plutarco en su Questiones Romanae o Agustín. Una interpretación semejante está, por otro lado, mucho más en consonancia con una tendencia que se observa en un elevado porcentaje de mosaicos pavimentales de época tardía en Hispania: temas banales y cotidianos, un cierto provincianismo y vanidad personal, escasas manifestaciones intelectuales, (recuérdese a este propósito la proliferación de mosaicos de caballos y circos, de escenas de caza, etc.). Sobre esto trataré más adelante. Pero el caso no queda ahí, en la interpretación forzada de la iconografia, va mucho más allá y se convierte en hiperinterpretación; de la iconografía pasamos al significado del complejo arquitectónico y a la función de la propia residencia y la propuesta termina siendo que La Malena - cito textualmente- ues un espacio sagrado, un cabirion, un monasterio o un lugar de culto, probablemente residen-

\footnotetext{
2 Me refiero a Dimas Fernández Galiano: Cadmo y Harmonia. Imagen, mito y arqueologia, JRA. 5, 1992, págs 162-177. Véase a propósito mi critica a sus propuestas y planteamientos en J. Arce: Las villae romanas no son monasterios", EspA, 65, 1992, págs. 323-330. La respuesta de Dimas Fernández Galiano en $A E s p A$. 65, 1992, págs. $331-334$ no me parece convincente y resulta ser una solicitud de disculpa por parte de Dimas hacia sus propios planteamientos y entraña auténticas contradicciones. Yo le reprochaba a Dimas Fernández el no aducir documentos válidos (en realidad no presenta ninguno) ni bibliografia para sostener su hasta ahora una simple hipótesis. Se justifica diciendo que «tal vez la fatiga - saturado como estaba por la lectura de estudios tan rebosantes de erudición farragosa como vacios de ideas - me inclinaron.. a no prodigar las citas» (Dimas Fernández Galiano I.c. págs. 331). Lamentable justificación para un investigador que además entraña un desprecio intolerable hacia sus propias lecturas. No es éste lugar para responder a las alegaciones de Dimas Fernández cosa que haré en otras páginas.
} 
cia de una comunidad de creyentes en los misterios de Samotracia... ". La consecuencia última está formulada de tal forma que pienso que no puede ser obviada, ya que adquiere dimensiones históricas: «de poco sirve estudiar los antiguos cabiria - continuo citando - para entender éste; por época y ambiente cultural conviene compararlo con otros monasterios o conventos que con el impreciso nombre de villae se vienen desconociendo en la bibliografia dedicada a la última romanidad en Hispania». En resumen: «Fraga, Santervás del Burgo, Quintanares de Rioseco, Centcelles, Torre de Palma y muchas otras villae hispanas, son conventos y monasterios" ${ }^{3}$. Se nos propone, pues, a los historiadores y arqueólogos, en función de una hiperinterpretación de la «imaginería», esto es, de la iconografía de los pavimentos, ver en las villae, no lo que siempre hemos considerado que eran, sino el lugar de retiro de comunidades religiosas paganas, centros de vida monacal pagana. Esta propuesta de algunos iconografistas que estudian los mosaicos es tanto más importante y a tener en consideración en cuanto que propone para la Hispania tardorromana una sociología totalmente diferente a la que ahora estamos o venimos interpretando; esto es, lo que entendemos que era, una sociedad de grandes propietarios romanos, ricos, productores, absentistas a veces, creadores de una economía local que define el periodo. En cambio, de la iconografía hemos pasado a la propuesta de la religiosidad pagana, compuesta de diferentes sectas, que se constituyen en la misma norma en el paisaje rural tardorromano. Consecuencia exagerada - diría- que viene de la mano de los estudiosos de los mosaicos.

El problema es que ésta interpretación no posee ningún fundamento ni en las tipologías y funciones que evidencian las villae de la $\mathrm{Pe}$ nínsula, ni en la documentación histórica a nuestra disposición.

Podemos comenzar por el mismo vocabulario empleado para designar lo que nosotros llamamos villae. Se pretende que son monas-

${ }^{3}$ Las dos citas textuales en Dimas Fernández Galiano: $. J R A, 5,1992$, pág. 176. terios o conventos. Estos son términos, cuando menos, inadecuados. La idea monástica o conventual, con su regla y sus normas inherentes es ajena al paganismo; es propia del cristianismo. El emperador Juliano intentó crear una «Iglesia» pagana ${ }^{4}$. Mme. Balty - recientementeha propugnado mediante el análisis iconográfico de los mosaicos de la localidad de Sarrin. en Oshroene, la pervivencia de grupos paganos aún en época muy tardia siglo vI-vII d. C., pero no de monasterios en esta región ${ }^{5}$. $\mathrm{Y}$ el reciente libro de G. Bowersock, Hellenism in Late Antiquity, no hace más que corroborar, para la Pars Orientis y para las remotas tierras de Arabia, esta permanencia del "helenismo» manifestada en pinturas, mosaicos y estatuas ${ }^{6}$. Desde luego en Hispania en el siglo IV no existían monasterios ni cristianos ni paganos?

Las villae o los edificios como el de Sarrin podian servir para la reunión de personas, que eventualmente, discutian en ellos de temas de interés común o de interés ideológico afin. Pensemos en las casas de los filósofos del ángulo occidental del agorá de Atenas. Este tipo de actos los puede promover cualquier persona en su residencia sin que ésta se convierta por ello en un monasterio. $\mathrm{Y}$ además ¿es un mosaico elemento suficiente para una afirmación de este tipo? Mi respuesta es que no.

El primer concilio de Caesaraugusta - destinado a condenar las doctrinas priscilianistas y celebrado en el año $380 \mathrm{~d}$. C.- contiene algunos cánones interesantes a este respecto. El canon 2 anatematiza a quienes se esconden en los cubículos ocultos de su casa o en los montes y a quienes acuden a villae de otros para celebrar reuniones (ne habitent latibula cubiculorum ac montium qui in suspicionibus per-

\footnotetext{
4 Sobre esto, aparte de los testimonios de la propia obra de Juliano, en cartas y discursos, ver las iluminantes páginas de J. Bidez: La vie de l'Emperor Julien, París, 1930 y W. Koch: Comment l'Emperor Julien tâche de fonder une Eglise païenne, Rev. Belge de Phil. et d'Hist. 6/7. $1927 / 8$, págs. I ss.; 49 ss.; 511 ss. y 1363 ss.

5 J. Balty: La mosaïque de Sarrin (Oshroene), Inst. Fr. d'Archeol du Proche Orient, Bibl. Arch. et hist. T. CLX Paris, 1990.

' G. W. Bowersock: Hellenism in Late Antiquity, Michigan, 1990.

7 Sobre esto cfr. J. Arce: AEspA, 65, 1992, págs. 326327.
} 
se'verant, sed cxemplum et praceptum custodiant et ad alienas villas agendorum conventum causa nom conveniamt, "ni se escondan en lo más apartado de su casa o de los montes aquellos que perseveran en estas creencias, sino que sigan el ejemplo de los obispos y no accedan a las villas ajenas para celebrar reuniones»). El lermino usado es villa. como también lo es en otro canon el 4 de contenido semejante: entre el 17 de Diciembre y el 6 de Enero, que nadie se ausente de la lglesia durante todo el dia, ni se oculte en su casa ni se vaya a su villa (nec sedere in villam), ni se dirija a los montes. Prisciliano mismo, dos años más tarde. expulsado de Burdigalia por el obispo, se estableció en la villa de Euchrotia y Procula - viuda e hija respectivamente de Atio Tiro Delfinio, fallecido profesor de la escuela bordelesa - Los seguidores de la secta priscilianista se reunian en villae de amigos, simpatizantes o encubridores; pero las villae seguian siendo villae, propiedades rurales de los grandes terratenientes; no conventos o monasterios.

El mosaico de "La Malena» no es pues, en mi opinión, otra cosa que un mosaico pagano que representa el matrimonio de los propietarios de la misma. matrimonio asistido y presenciado por los dioses y genios que lo presiden. Ya Plutarco en sus Quaestiones Romanae se preguntaba: “_Por qué en las bodas se encienden cinco lámparas? Porque los contrayentes piensan - responden Plutarco-que se precisa la ayuda de cinco dioses, esto es, el perfecto Júpiter, la perfecta Juno, Venus, la diosa de la «Persuasión» y especialmente Diana, a quien las mujeres invocan cuando les sobrevienen los dolores del parton ${ }^{x}$. A estos dioses se pueden añadir otros, el Genio protector de la casa y otros a los que se quiere o tiene devoción especial - Mercurio - esto es, el dios de la prosperidad y los negocios; los dioscuros, etc. que son los representados en el mosaico de «La Malena” (figura 1).

Lo que queda en la historia de la Hispania tardorromana en el clamoroso caso de los mosaicos de La Malena es, una vez más, una viIla, una explotación agricola, de un possessor

\footnotetext{
${ }^{*}$ Plut. $Q R, 2$.
}

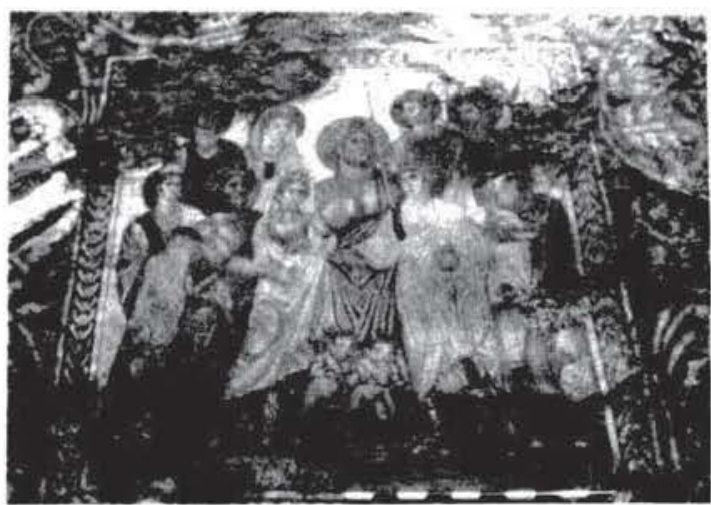

Figura I Mosaceocon la represcntacion del matrmono de los propictarios. Iilla de La Malena (Zarago/a).

rico, pagano, que «regala» a su esposa (y a los amigos y huéspedes) el pavimento con su retrato matrimonial bendecido y sancionado por los dioses de siempre ${ }^{\circ}$. La Malena no nos altera - creo yo - la historia religiosa del paganismo hispánico del siglo iv con complicadas - e innecesarias - historias de los ritos de los misterios de Samotracia en un apartado rincón de la Tarraconense.

\section{MATERNUS Y CARRANQUE}

Otro mosaico que ha suscitado discusion y que ha traido a colación un importante personaje de la historia de la Hispania tardorromana es el del cubiculum de la villa de Carranque. Hace años tuve la oportunidad y la fortuna - por qué no decirlo- de ser el primer editor de este espléndido pavimento cuya problemática iconográfica con ser extremadamente importante por su originalidad en el repertorio hispánico, está ampliamente superada por la inscripción que está en la tabula ansata representada en la entrada de la habitación. Como es bien sabido la inscripción dice: Ex oficina Ma... ni pingit Hirinius / utere felix Materne hunc cubiculum ${ }^{10}$ (figura 2).

\footnotetext{
"Los retratos de los propietarios en los mosaicos de las villae romanas son bien conocidos y frecuentes; en Piaza Armerina, en Pedrosa de la Vega, en Tossa del Mar, en la villa de "El Olivar del Centeno", Cácere; en Centeelles. etc.. por no hablar de los numerosisimos ejemplos de sarcófagos.

10 J. Arce: El mosaico de "Las metamorfosis" de Carranque, $M M, 27,1986$, págs. 365-374
} 


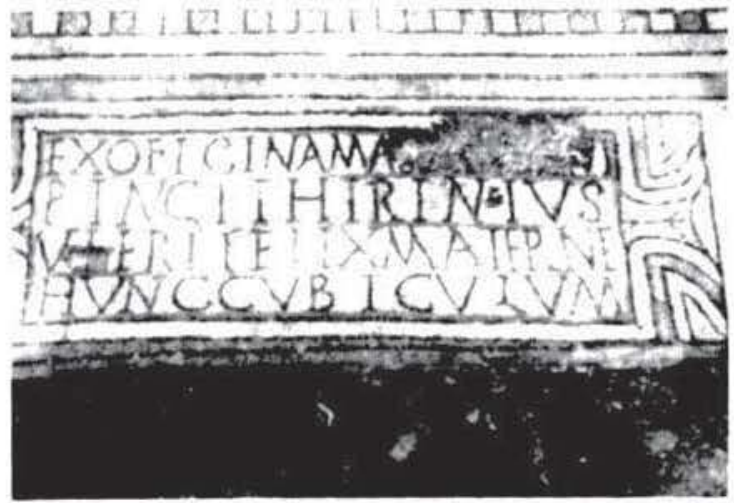

Hegra 2. Detalle de la mscriperon de un mosateo de la villa de (arranque (Toledo)

Recientemente P. Le Roux en $L$ Anece Epigraphique $"$ ha propuesto la restitución del nombre del jefe de la officina como un tal Mas(culi)nus o Mas (cli) nus, posibilidad que queda abierta.

Parece lógico pensar que Maternus era el propietario de la villa (aunque podria también ser el utente o usuario habitual del cuhiculum). Sobre este tema yo escribi: «Maternus, frecuente nombre en la meseta hispánica desde antiguo. pero abundante en época tardia, incluso en altos dignatarios que pertenecian a la familia imperial» ${ }^{12}$. De aqui se ha ido al paso siguiente: el propietario era Maternus Cinegius, que fue prefecto del pretorio en Oriente con Teodosio I. Además: incluso se sugiere la posibilidad de que Materno Cinegio estuviera enterrado en Carranque, ya que sabemos que su viuda Acanthia trasladó su cadáver desde Constantinopla a Hispania ${ }^{1 !}$.

Conviene detenerse un momento es este punto. Yo mismo también escribi a propósito del propietario de la villa de Carranque: «que era rico, no cabe duda, por la extensión de la propiedad y la riqueza que se vislumbra. Que fuera pagano, no es de extrañar a la vista de la temática de sus mosaicos (yo conocía entonces sólo el cubiculum al que nos referimos). Los frecuentes hallazgos de este tipo de mosaicos

\footnotetext{
11. AEp, 1989, n. 470 bis,

12 Arce, 1.c. (n. 10) págs. 371-372

is Asi Dimas Fernández Galiano: JRA. Suppl. 1992; id. La villa de Materno, Revista de Arqueologia. 127. 1991. ping. 26 ss.
}

en Hispania demuestran cada ve/ más, en mi opinion. la todavia profunda paganización de la sociedad tardorromana en Ilispania, especialmente en ambitos rurales" "Esta conclusion mia puede - y debe- ser discutida, obviamente. La temática pagana en el repertorio iconográfico musivario no implica for rosamente el paganismo automatico del propietario que, a veces. incluse no intervenia en la elección del tema directamente. Los repertorios al uso de las officince eran repetitivos y monotonos. $Y$ la cristiana Projecta tenia en su ajuar personal objetos de plata decorados con escenas mitológicas paganas. Y el calendario de Filocalo, del 354 es de un cristiano. Habia una ambigüedad y una frontera dificilmente discernible entre paganismo y cristianismo entre la sociedad (sobre todo culta) en el siglo Iv d. C. ${ }^{15}$. Este es un tema complejo. sobre el que se ha escrito ( $y$ escribirá) mucho y que podria ser objeto de largo debate. Pero aún reconociéndolo y siendo conscientes de ello, y de que la identificación, mosaico de tema pagano igual a propietario pagano, no es ni mucho menos mecánica, existen algunos casos más evidentes o más claros que otros. En Centcelles - del que hablaremos más adelante - no hay ambiguiedad alguna: el programa iconográfico está calculado y pensado para rodear al espectador de un ambiente simbólico cristiano.

Materno Cinegio fue un personaje cuyos rasgos de definición en la alta administración teodosiana no ofrecen ambigüedades, al menos en un punto: fue un ardiente perseguidor del paganismo, un gran destructor de templos, sacrificios e idolos "in. Prefecto del Pretorio de la Pars Orientis del 384 al 388 sabemos que incluso en este celo antipagano se excedió más alla de las propias disposiciones y voluntad del Emperador imperator christianissimus-Teo-

\footnotetext{
i4 Arce, I.c. (n. 10) págs. 374

in el caso de Projecta parece que el marido era pagano y no su mujer. Sobre el tema en general cfir. M. R Salzman: On Roman Time, Univ. Cal. Press. 1990. pág. 225 ss. con acertadisimas observaciones

- Sobre Materno Cinegio efr. J. Matthews: Western Aristocracies and Imperial Court. A.D 364-425, Oxford 1975. págs. 110-111 y passim cfr. A.H.M. Jones - Martindale-Morris: The Prosopography of the Later Roman Em pire, (1). 1971, S.V. que duda, razonablemente, de su ori. gen hispano.
} 
dosio. Las medidas contra el paganismo de Teodosio. que podemos calificar de sustanciales. no tienen lugar hasta el 391. Y aún asi, con anterioridad, segùn el historiador Zósimo, uencargó a ( inegio, el prefecto del pretorio enviado a Egipto, con la orden de llevar a todos la prohibicion del culto a los dioses y de clausurar los recintos sagrados, y para que mostrase a los alejandrinos la imagen de Máximo (estamos pues entre el 384-388), la expusiera públicamente $y$ anunciase al pueblo que habia correspondido a aquél ocupar el trono a su lado. Cinegio, además de cumplir en este punto la orden, cerró a lo largo de Oriente, de todo Egipto y en la misma Alejandría, los accesos a los templos y prohibió los sacrificios que habian sido celebrados desde siempre y cualquier ceremonia ancestral" ${ }^{17}$. En un segundo viaje por Oriente - que incluyó también Egipto-en el último año de su vida, tomó medidas constantemente para la supresión del paganismo ${ }^{1 x}$, y él fue quien con la ayuda de Marcelo de Apamea derribó un templo - según testimonia la $H E$ de Teodoreto ${ }^{19}-$, y quien, animado por su esposa y un grupo de monjes sin permiso del Emperador según relata Libanio ${ }^{20}$ — destruyó otro templo en Oshroene. Murió durante el viaje de regreso a Constantinopla y mereció ser enterrado - nada menos- que en el mausoleo de la iglesia de los Santos Apóstoles, aunque sólo fuera transitoriamente, ya que al año siguiente - 389- su esposa Acanthia lo trasladó a Hispania ${ }^{21}$. Este es el único dato que ha permitido a algunos historiadores inferir que era un hispano de nacimiento- podemos hipotizar que su esposa lo era, pero tampoco tenemos ningún dato para asegurarlo.

Dicho esto, mi interrogante es éste: ¿ podemos imaginarnos a Materno Cinegio disfrutando de un cubiculum en su villae de Carranque rodeado de escenas que - permitaseme - voy a llamar eróticas, recuerdo y presencia de historias amorosas como la de la ninfa Amymone, el bello Hylas - con Hércules presente- el

\footnotetext{
i) Zos., IV, 37

is Cons. Const. s.a. 388.

iv Theodoreto, $H E, \mathrm{~V}, 21,7$.

20 $\mathrm{Or}, \mathrm{XXX}, 46$

*Cons. Const, s.a. 388.
}

"voyeur" Acteon descubriendo la desnudez de Diana o incluso la amorosa y secreta cita de Piramo y Tisbe? No sé si la moral victoriana tenia cabida en el ánimo de Materno Cinegio y probablemente era un gran hipócrita. Pero prefiero pensar que aqui no hay ambigüedad: Materno, el de Carranque, tenía un sentido de la vida muy distante del espiritu que animó a $\mathrm{Ci}$ negio y prefiero seguir proponiendo que era un pagano y que el Prefecto del Pretorio de Teodosio no tiene nada que ver con la espléndida villa de Carranque. La tentación de los mosaistas de dar nombres de personajes históricos y de encontrar propietarios conocidos a sus villae, es muy fuerte - hay ejemplos clamorosos, Piazza Armerina-; pero sirven más los prudentes testimonios contrastados.

\section{CENTCELLES}

Debo, por fuerza, comentar, aunque sea rápidamente otro complejo de mosaicos que se han relacionado desde siempre con problemas históricos de la época tardorromana en Hispania: Centcelles. Centcelles es una crux para historiadores, arqueólogos e iconografistas. De nuevo estamos ante un caso en el que la tentación de asignar propietarios notables ha traicionado, quizás, a los arqueólogos. Si H. Schlunk y Th. Hauschild pensaron en que podria ser el mausoleo de Constante - uno de los hijos de Constantino-, siempre con prudencia, pero con decisión, la última propuesta eleva la identificación a los límites de lo inverosímil y de la hiperinterpretación. A. Arbeiter ha escrito reiteradamente que en los mosaicos de Centcelles no hay sino cuatro Emperadores, o mejor, dos Emperadores y un César y un Emperador-usurpador: Magnencio, en posición preeminente; Constancio II, aunque senior y único legitimo, en posición subordinada; Decencio, el César de Magnencio y el emperador-usurpador de apenas 10 meses de duración, Vetranio. Todo este programa habría sido inventado e impulsado por Magnencio que - según Arbeiterpretendia de ese modo ofrecer una especie de concordia imperatorum, dedicando (?) el monumento a Constante, pero representándose él 
mismo en la cupula junto a Constancio II y los otros dos. El mausoleo de Centcelles se ha magnificado en exceso en la. o para, la historia tardorromana de la diocesis Itispaniarum ${ }^{22}$.

En toda la discusión sobre Centcelles creo que quedan claros y definitivamente asentados una serie de datos que pueden ser los siguientes, aceptados incluso por el propio Arbeiter: a) el retrato famoso no obedece a los canones de la retratistica constantiniana y no es identificable con Constante (figura 3): b) el testimonio de Athanasio. contrariamente a la opinion de Schlunck. no significa otra cosa que Constancio II fue culpable de ni siquiera haber honrado la memoria de su hermano con un mnemeion. Athanasio es un testimonio contrario a la identificación de Cencelles como Mausoleo de Constante. Dicho esto, de la tesis de Arbeiter quedan solo una serie de afirmaciones hipoteticas en extremo. cuando no contrarias a la misma lógica de la historia y la politica y mentalidad del periodo: a) Que Magnencio dedico el monumento, que no seria ya la tumba. sino sólo el cenotafio, a Constante, a quien acababa de derrocar y mandar asesinar. No es im-

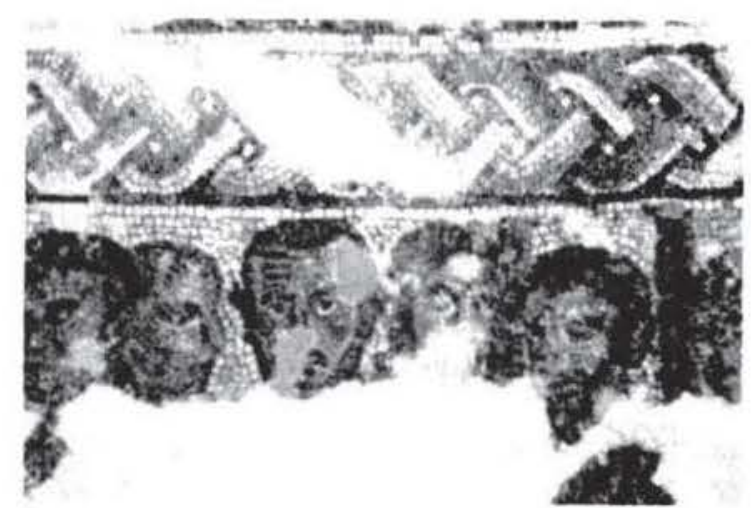

Figura 3. Detalle de los ferratos en la escena de caceria del mosaico de (centelles (Tarragona).

77 Sobre Centcelles la última teoria está expuesta en A. Arbeiter, Madrider Mitteilungen, 30. 1989, págs. 284. 331 (con toda la bibliografia colateral), ver también id: El mosaico de la cúpula de Centeelles y el derrocamiento de Constante por Magnencio, Boletin Arqueológico. Tarragona, 1988-89. n." 10-11, págs. 193-244 (en colaboraciòn con D. Korol); mi posición fue expresada en Retratos imperiales tardo-romanos de Hispania: la evidencia epigrafica, AEspA. 50/51, 1977-78, pàgs. 253-268 y en 1. Arce, Fumus Imperatorum. Madrid, 1988. probable que un Emperador usurpador tenga su reconocimiento por parte de sus partidarios 0 incluso de su rival. Arbeiter pone algunos ejemplos tomados de la $\mathrm{H}^{+}$Augusta - que no resultan válidos porque no se trata de situaciones semejantes (por ej. Severo Alejandro que merecio un cenotatio en Germania y una tumba en Roma ". No menciona. sin embargo, el mas importante y significativo de todos, esto es, el pasaje de Tirannorum Triginta que en la lita de Aureolo (usurpador contra Galieno y que mas tarde fue derrocado por Claudio el (iótico) que recibió. de parte de el Gótico. el honor de un puente y un sepulcro. La Historia Augusta define muy bien este tipo de acción y describe el monumento: atque illic ut trammum sepulcho humiliore donavit. El problema es que Aureolo no fue un usurpador del poder de Claudio el Gótico - como era el caso de Magnencio contra Constante y contra Constancio II. sino un usurpador contra Galicno. Hasta un usurpador merece un tumulus o, al menos. Io puede merecer: pero el usurpador no se dedica a si mismo dicho monumento, como pretende Arbeiter que hizo Magnencio en Centcelles; b) que este monumento propugnado por Arbeiter en Centcelles seria un monumento que, al situar a Magnencio, Decencio y Vetranio al lado de Constancio ( $y$ éste en posición inferior) en vez de provocar la concordia imperatorum provocaria la ira imperial porque es desconocer la concepción del poder de Constacio Il imaginar que este hecho le hubiese dado satisfacción. Todo lo contrario ${ }^{24}$; c) que el monumento debió de ser hecho. si aceptamos la propuesta de Arbeiter en el espacio de ocho meses (a lo

21 Arbeiter: Boletin Arquentogion (citado supra) n. I13. Severo Nlejandro fue un emperador amado por sus soldados (ISevilex, 63) a pesar de haber sido asesinado por un pequeño grupo de ellos. Normalmente las acciones de honrar al Emperador asesinado violentamente por una facción del ejército son posteriores en mucho a su derrocamiento, y vienen de sectores contrarios al hecho o del propio senado, y obedecen a una politica de conciliacion y legitimacion del Emperador-usurpador. Pero éste no se dedica a si mismo el monumentu, como pretende Arbeiter que hizo Magnencio en Centeclles.

24 Basta leer las palabras de Amiano: sub eo nemo celsum aliquid acturus (21,16,3): ver también 21,16.1: Imperatoriac atcoritatis cothurnum ubique custodiens; $21.16 .9 \mathrm{etc}$ 
más 10) _- duración de la usurpación de Vetranio. ¡Dos millones de teselas son muchas teselas! - y y d) el objetivo del monumento, la propaganda de la Concordia, no se podia alcanzar o era absurdo que se alcanzara haciendo un monumento en la Tarraconense tan poco visible. tan escasamente aparente y visitable que pretendiese una difusión amplia de los intereses de Magnencio.

En definitiva; por qué no dejar la historia como está en nuestra evidencia disponible, esto es, que Constante murió en Elne, cuando venía hacia Hispania, a manos de los esbirros de Magnencio. Que su cadáver desapareció y no se encontró - frecuente fin de los Emperadores derrocados violentamente- y que por ello no fue trasportado al mausoleo imperial de Constantinopla. Y que Constancio - en fin-como le recrimina Atanasio no hizo nada por procurarle un recuerdo digno en ninguna parte. Hay que recordar que Constancio no respetó ni aceptó nunca compartir el poder con sus dos hermanos ni con nadie - incluso Juliano ${ }^{25}$. $Y_{i}$, por qué no aceptar que los mosaicos de Centcelles son para una tumba de un alto dignatario o personaje cristiano - un obispo, el propio Materno Cinegio- que participó y estuvo cerca de la majestad de los Emperadores? ¿Y qué ocurriria si Centcelles no es un mausoleo, sino un aula de recepción perteneciente a la villa? Esta hipótesis será objeto de una nota que publicaré próximamente.

He comentado hasta ahora los mosaicos que de forma más significativa se han puesto en relación con problemas históricos relevantes de la época tardo-imperial en Hispania.

Debo, en fin, aludir a otros mosaicos, o a los mosaicos en su conjunto.

\section{EL MENSAJE DE LOS MOSAICOS}

Podemos volver al principio, a la cultura de los grandes propietarios tardorromanos de Hispania. En este punto hay que subrayar que con los mosaicos solos es dificil llegar a conclusiones especificas sobre el particular. El reciente catálogo de Juan Gómez Pallarés sobre

\footnotetext{
${ }^{25}$ Por ejemplo Amiano Marcelino 16.2 .68 y ss.
}

los mosaicos con inscripciones - que será publicado próximamente - pero a cuyo manuscrito he tenido acceso por su amabilidad, pone de manifiesto, entre otras cosas, el carácter banal, reiterativo y, en todo caso, vanidoso y de autoafirmación de los propietarios, que dejan constancia escrita de sus intereses. En un mosaico de Portugal (Viamonte, Portalegre) el propietario - o el artesano que lo realizó- advierte al visitante o al encargado de la limpieza de la habitación de que tenga cuidado con la escoba al barrer no sea que pueda destrozar las teselas: scopa aspra tesellam ledere noli -; otras veces se trata simplemente de la expresión de un deseo, de un augurio de bienestar o de felicidad: «Si Cardilio y Avita viven, su casa ( $t u$ rris) está feliz» (Torres Novas, Portugal); o $\mathrm{Vi}$ talis que hizo declaración expresa para recuerdo de todos los integrantes de sus posesiones y eventuales visitantes de que mientras él viviera, no habría problemas para sus feudos: salvo Vitale / felix Tur(r)issa, reza el mosaico de su villa de Torre del Mar, en Gerona; una breve y rotunda forma de expresar el sistema de dependencia de los campesinos con el dominus y el régimen del colonato. Me pregunto, en fin, $\mathrm{si}$ en el famoso mosaico de El Ramalete con Dulcitius, la referencia no es más bien al caballo que al possessor; porque los mosaicos con nombres de caballos famosos son - como era de esperar - abundantes en una sociedad que amaba más las carreras que la filosofia. En la villa romana de Cuevas de Soria, hoy en el Museo Arqueológico Nacional, un mosaico ostentaba el monograma que escondia el nombre de la familia propietaria, que probablemente servía también para marcar los caballos de sus propiedades ${ }^{26}$. Nunca hasta ahora se ha descifrado este monograma. Creo que se puede tratar de Faventini (figura 4), una familia que, una vez más y como es frecuente en los mosaicos tardíos de Hispania, deja constancia de su nombre o de su retrato en los mosaicos que adornan su villa, como ocurre en La Malena (los espo-

\footnotetext{
${ }^{26}$ Sobre este tipo de monogramas en los caballos cfr. J.H. van der Werff: Notes on a graffito from the Basilica Emilia, Bulletin Antieke Bescharing, XLVIII, 1973, págs. 83-90 con J. Arce: Los caballos de Símaco, Faventia, 4.I. 1982, págs. $35-44$.
} 


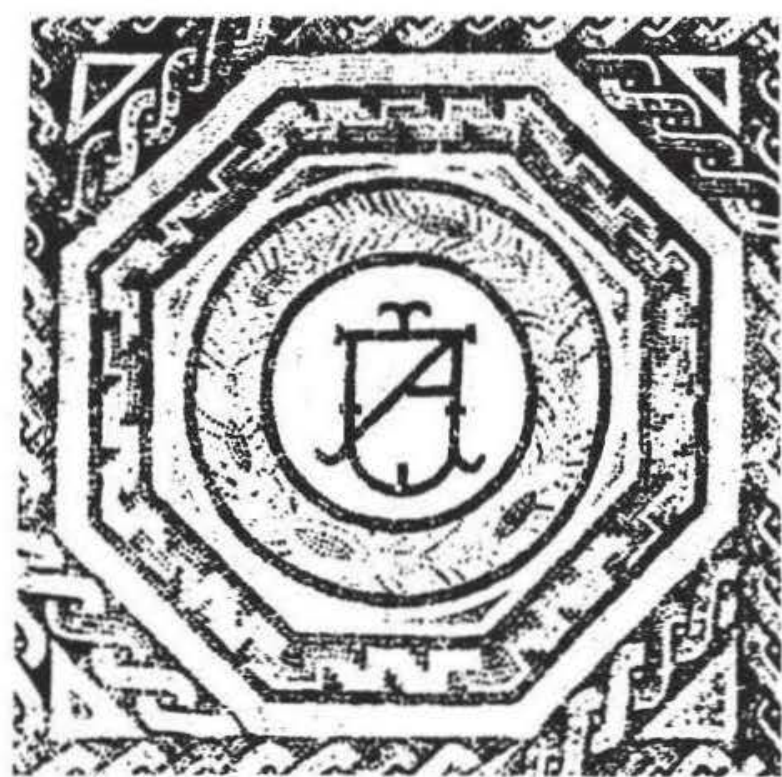

ligura t. Monograma del mosateo de la villa de Cuevas de Soria.

sos retratados); en Carranque (Materno), en Torre del Mar (Vitalis): en Torres Novas (Cardilius y Avita); en Pedrosa (los retratos de la familia bordeando el tema de Aquiles en Skyros) o en la villa de «El Olivar del Centenon (Cáceres) ${ }^{27}$.

Hay un mosaico, el de los Siete Sabios de Mérida, que junto al de las Musas de Arróniz, podía ser interpretado como expresión de una cultura filosófica de sus propietarios. Quiero sólo recordar - como lo ha hecho P. Brownque en unas letrinas de Ostia Antica aparecen estos mismos filósofos ofreciendo a los sentados clientes, severos y juiciosos consejos sobre "el modo correcto de defecar" (P. Brown). Esto es un hecho muy significativo por lo que respecta a lo que los antiguos entendian y hacian con sus decoraciones de repertorios y de lo que nosotros por el contrario podemos hacer o no hacer con ellas.

Creo que por fin $-y$ poco a poco- estamos casa vez más ajenos a aquella linea interpretativa de los mosaicos como "fuente para la

\footnotetext{
2" Agradezco al Dr. Emilio Rodriguez Almeida el desciframiento del monograma de Cuevas de Soria. Sobre estos individuos, sus vanidades, aspiraciones y fatuidades cfr. L. Robert: Hellenica, IV, 1948, págs. 109-110 (por ejemplo) y R. MacMullen: HStCIPh, 1964, págs. 305-316.
}

economia de la Hispania tardian. Algunos mosaicos africanos representan escenas de la vida rural. Un ejemplo famoso es el llamado del Dominus Julius, hoy en la Museo del Bardo en Túnez. En ellos se observan gentes cazando. ocupados en actividades de pesca, $o$ de siega $o$ de siembra; el transporte y recolección de productos, no faltan en las imágenes de estos beIlos ejemplares. El problema de la interpretación de las escenas, desde el punto de vista del historiador, reside en saber si realmente ofrecen escenas tomadas de la vida cotidiana u obedecen a patrones artísticos estereotipados. $\mathrm{K}$. Weitzmann ha observado recientemente al hablar de estos mosaicos que ude la misma forma que las representaciones bucólicas, es dificil determinar si los artistas trabajaron por una directa observación o derivación de tipos convencionales y tradicionales". El artista dependía de textos populares (y popularizados) como los de Oppiano o el pseudo-Oppiano y resulta dificil saber lo que es de tradición helenisticoalejandrina o lo que efectivamente pudo ser la realidad $^{2 x}$.

Para la historia tardorromana de la diócesis Hispaniarum los mosaicos que decoran los pavimentos de las numerosas villae o viviendas urbanas tienen un valor en si mismos, como evidencia del trabajo artesanal y decorativo de los diversos complejos arquitectónicos y de la diversa importancia dada a las distintas habitaciones. Valen por lo que significan las distintas officinae que están atestiguadas en la Peninsula - Janine Lancha ha escrito sobre este tema páginas definitivas en los Melanges de la Casa de Velázquez ${ }^{24}$; y destaca entre ellos en Hispania la inscripción de Carranque donde está perfectamente señalada la división del trabajo: la officina y su maestro y el pintor que concibe el cartón ${ }^{30}$. Existen pocos ejemplares que demuestren tan evidentemente estas dos actividades; pero la inscripción de un mosaico del museo de Tebas, en

\footnotetext{
* Sobre esto cfr. J. Arce: El último siglo de la España romana, passim, Madrid, 1982.

24 J. Lancha: Les mosaistes dans la vie economique de la Peninsule lberique, $M C V .20,1984$, págs. 45-61.

wo Sobre ello: J. Arce: El mosaico de "Las Metamorfosisn de Carranque, $M M, 27,1986$, págs. 365-374.
} 


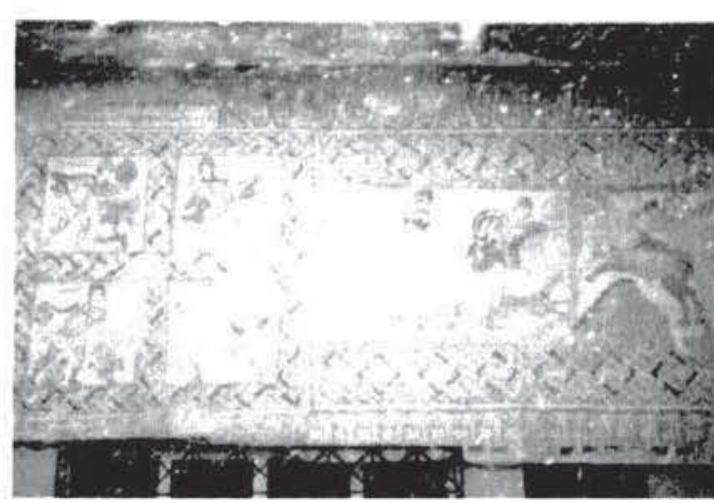

I ggura 5. Mosarco del Musco de lebas.

Grecia, de los siglos v-vi d. C. complementa nuestra información al respecto, ya que en ella se explica que mientras un tal Demetrios hizo el mosaico, otro lo concibió e imaginó su tema. Dos acciones distintas $\mathrm{e}$ independientes entre si; pero sobre todo independientes del dueño o del comitente, que no intervenia para nada en el asunto "(figuras 5 y 6 ).

La inscripción merece ser citada en extenso:

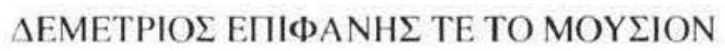
IIOEI

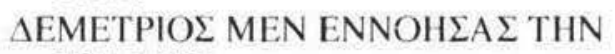

ГРАФНN

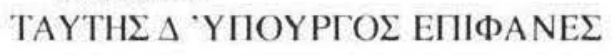

EYNOYETATOE

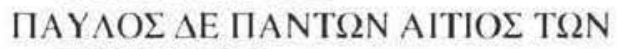
EYПРЕП $\Omega N$

\footnotetext{
"Sobre este tema, véanse las iluminantes conclusiones de E. Kitzinger en Artistic Patronage in Early Byzantium, en Committenti e Produzione artistico-letteraria nell 'alto medioevo occidentale. Settimane Spoleto. XXXIX, 1992, págs. 33-35 (especialmente 52-55), con A. Cameron: JRA, 5, 1992, págs. 178-185.
}

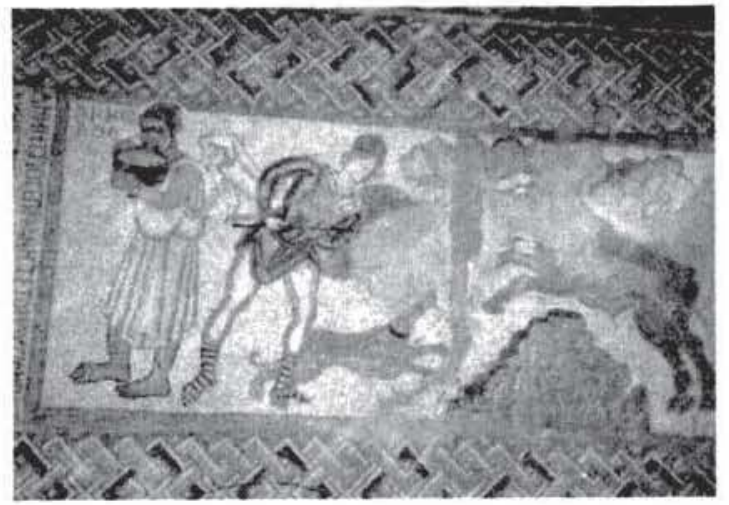

I igura 6. Detalle de la inscripcion del mosatico del Museo de Tebas.

\section{IEPEY $\Sigma$ TE KAI $\Theta E I \Omega N \Lambda O \Gamma \Omega N$ $\triangle \mathrm{I} \triangle \mathrm{A} \Sigma \mathrm{KA} \Lambda \mathrm{O}$}

Cuya traducción seria ésta: «Demetrio y Epifanes hicieron el mosaico; Demetrio, por su parte, inventó el dibujo; y el ingenioso Epifanes fue el creador del mismo. Por fin, Paulo sacerdote y maestro de las palabras divinas, fue causa de (proveyó) todo lo necesario".

El mosaico está siendo objeto de estudio por mi parte y será publicado en breve. Se trata de un calendario con la representación de los meses (el personaje central representa el mes de Agosto) en un ámbito cristiano.

Quienes estudian los mosaicos deberian tener en cuenta que ellos sólos, por sí mismos, no pueden contarnos toda la Historia. Se necesita precisamente la Historia y su contexto para comprenderlos ${ }^{12}$.

\footnotetext{
1: Agradezco muy sinceramente a Walter Trillmich. Pierre Gros y a Emilio Rodriguez Almeida el haber leido este manuscrito y haberme hecho indicaciones preciosas. La responsabilidad del texto es exclusivamente mia. A Fabienne Burkhalter que ha sido, como siempre, quien me ha dado, con sus criticas y sugerencias, una ayuda inestimable en algunos aspectos. En fin. a Gonzalo Sảenz, de la Escuela Española de Historia y Arqueologia del C.S.I.C. de Roma, por haber tenido la gentileza de ayudarme en el dibujo reconstructivo.
} 